\title{
Identification of Specific Variations within the HE, S1, and ORF4 Genes of Bovine Coronaviruses Associated with Enteric and Respiratory Diseases in Dairy Cattle
}

\author{
ANNE-MARIE GÉLINAS, AM-J SASSEVILLE, AND SERGE DEA \\ Centre de Recherche en Microbiologie et Biotechnologie, INRS-Institut Armand-Frappier, \\ Université du Québec, Laval, Québec, H7V $1 B 7$.
}

\section{INTRODUCTION}

The bovine coronavirus (BCV) is the causative agent of enteric diseases including neonatal calf diarrhea (NCD) (Dea et al., 1980; Mebus et al., 1973), winter dysentery (WD) (Benfield and Saif, 1990; Dea et al., 1995), and chronic shedding in adult cattle (AD) (Tsunemitsu et Saif, 1995). BCV can also infect the upper respiratory tract of growing calves causing pneumonia (Chouljenko et al., 1998; Reynolds et al., 1985). The respiratory $\mathrm{BCV}(\mathrm{RBCV})$ is now recognized as an important agent associated to shipping fever (Storz et al., 1996). The virion possesses a single stranded, non segmented RNA genome of positive polarity, and is made of 5 structural proteins: the nucleocapsid phosphoprotein $(\mathrm{N}: 52 \mathrm{kDa})$, the matrix glycoprotein (M: $25 \mathrm{kDa})$, the peplomer glycoprotein (S: $200 \mathrm{kDa})$, the small membrane protein $(\mathrm{E}: 9.5 \mathrm{kDa}$ ) and the hemagglutinin esterase glycoprotein (HE: $140 \mathrm{kDa}$ ) (Spaan et al., 1988). Both S and HE are able to agglutinate red blood cells and elicit production of neutralizing antibodies (Dea et Tijssen, 1989; Deregt and Babiuk, 1987; Vautherot et al., 1992). The S protein has an important role to play in tropism being responsible for binding to the host cell (Spaan et al., 1988). The regions situated between the $\mathrm{S}$ and $\mathrm{M}$ genes (ORF4 and ORF5) may also be implicated in the tropism of coronaviruses (Mounir et al., 1992). 
Considering that genomic variations may lead to antigenic diversity, changes in tropism and virulence of field $\mathrm{BCV}$ strains, the $\mathrm{S}$ (S1 subunit) and HE genes, and the ORF4 and ORF5 regions of enteric BCV and RBCV strains, have been cloned and sequenced. Data were compared to those of the reference Mebus strain associated with NCD.

\section{METHODS}

The Mebus strain of BCV (VR 874), as well as the porcine hemagglutinating encephalomyelitis virus HEV67N strain (VR 740) were obtained from the ATCC. The reference RBCV strain OK-0514 was provided by J. Storz, Louisiana State University. The OC43 strain of human coronavirus was obtained from P.J. Talbot, INRS-Institut Armand-Frappier, Laval, Canada. Field strains of BCV associated either to NCD (BCQ.571, BCQ.1523) or WD (BCQ.2590 and BCQ.7373) were obtained from Quebec dairy herds (Dea et al., 1995). RBCV BCQ.3994 strain was isolated from the lung of a dysphneic calf from a dairy farm in Southern Quebec, whereas BCO.43277 and BCO.44175 isolates, associated with pneumonia in Ontario dairy farms, were obtained from S. Carman, OVC, University of Guelph, Ontario. BCV isolates were grown in the presence of bovine pancreatic trypsin in HRT18G cells, a cell line derived from human rectal adenocarcinoma.

For serological studies, the MAbs 1D6-2, 1D6-3 and 9F2-1R directed to the HE of Quebec WD reference strain BCQ.2590 (Milane et al., 1997), as well as rabbit hyperimmune sera to the Mebus (5801) and the BCQ.2590 strains, were tested for their capacity to inhibit the HA activity of the various $\mathrm{BCV}$ isolates. The HA, acetyl esterase (AE) and RDE activities of the BCV isolates tested were determined as previously described (Dea et al., 1995).

For genomic studies, genomic RNA was extracted from concentrated virus by the method described by Chomczynski and Sacchi (1987). The approach of reverse transcription (RT) followed by PCR was used to amplify the $\mathrm{S} 1$ subunit and HE gene, as well as the ORF4 et ORF5 regions, of the coronaviruses (Dea et al., 1995). Primers were choosen according to the cDNA sequence of the Mebus strain of BCV (Parker et al., 1989). cDNA fragments were cloned in $T$ vector pCR2I (Invitrogen $\mathrm{Co}$ ) and sequenced using an Automated Laser Fluorescent DNA sequencer (Pharmacia LKB).

\section{RESULTS AND DISCUSSION}

The capacity of $\mathrm{BCV}$ isolates to bind to 9-O-acetylated sialic residues present at the surface of erythrocytes at different incubation temperatures is a biological property which permits to distinguish among BCV field strains 
(Dea et al, 1995). In our study, HA titers of BCV strains associated to WD, which varied between 1280 and 2560 , decreased significantly when the incubation $\mathrm{T}^{0}$ switched from $4^{0} \mathrm{C}$ to $37^{\circ} \mathrm{C}$, due to the activation of the higher $\mathrm{RDE}$ activity of these strains. For RBCV and NCD strains (HA titers of 640 to 5120), the capacity to destroy the host cell receptors was not influenced by the variations of incubation T, except for the BCQ.1523 strain which appeared to possess minimal $\mathrm{RDE}$ activity. The $\mathrm{AE}$ activities of the $\mathrm{WD}$ and RBCV strains were comparable, and appeared superior to that of NCD strains. Anti-HE MAbs 1D6-2, 1D6-3 and 9F2-1R have shown little activity against BCV Mebus and BCQ.571 strains, IHA titers being lower than 1/40. However, IHA titers of at least 2560 were obtained with MAbs 1D6-2 and 1D6-3 for all the other strains tested. MAbs 9F2-1R reacted only weakly against Ontario RBCV strains BCO.43277 and BCO.44175.

Table 1: Primers used for the amplication of the $\mathrm{S}$ (S1 subunit) and HE genes and ORF4 and ORF5 regions of $\mathrm{BCV}$ strains

\begin{tabular}{lll}
\hline Primer & \multicolumn{1}{c}{ Sequence } & Amplified region \\
\hline S1.Ad5 sens & 5' GGATCC GGATCC GCC GCC GCC ATG & \\
& TTT TTG ATA CTT TTA ATT TCC 3' & S1 subunit of S \\
S1. Ad5 AS & 5' GGATCC GGATCC TCA TCT ACG ACT & S1 subunit of S \\
& TCG TCT TTT TG 3' & \\
HE.Ad5 sens & 5' GGATCC GGATCC GCC GCC GCC ATG & HE glycoprotein \\
& TTT TTG CTT CTT AGA TTT GTT C 3' & \\
HE.Ad5 AS & 5' GGATCC GGATCC TCA CTA AGC ATC & HE glycoprotein \\
& ATG CAG CCT AGT ACC 3' & \\
BCV.5327 sens & 5' GGATCC GGATCC ATG TGG TGG TTG & ORF4 and ORF5 \\
& TTG TGA TGA 3' & \\
BCV.ORF4 AS 5' GAATTC GAATTC AAC GTC ATC CAC & ORF4 and ORF5 \\
& ATC AAG AAC 3' & \\
\hline
\end{tabular}

For the HE gene, the majority of the nucleotidic variations were silent mutations. The substitution of a leucine $(\mathrm{L})$ by a proline $(\mathrm{P})$ residue at aa position 5 , and the substitution of a serine $(\mathrm{S})$ by a proline $(\mathrm{P})$ at aa position 367 for all of the BCV and RBCV strains studied, when compared to the reference Mebus strain, had already been reported (Dea et al., 1995; Zhang et al., 1991). The substitution of an aspartic acid (D) by a glycine (G) at aa position 66 seems to be specific to the RBCV strains.

For the S1 subunit of the S gene, a total of 7 aa changes were observed among the enteropathogenic strains. Only one of these variations (aa 509) was located within the hypervariable region (aa 452 to 593). The inclusion of an Asp residue (aa 196), observed only for both WD strains, did not result in 
the appearance of an additional glycosylation site. A Met residue at aa position 256 appeared to be specific to enteropathogenic strains. Five substitutions were identified in the $\mathrm{S} 1$ subunit of $\mathrm{S}$ gene of $\mathrm{BCV}$ strains having a respiratory tropism. Two of these aa substitutions (aa 510 and 578) had already been reported (Chouljenko et al., 1998), and the 3 other (aa 256, 362 and 691) were observed only in case of Ontario RBCV strains. Chouljenko et al (7) had identified 5 other variations specific to RBCV strains situated in the N-terminal of the S1 gene (aa 11, 115, 118, 173 and 179). The latter were also present in the $\mathrm{S} 1$ sequences of some enteropathogenic strains as well as the substitutions reported at aa positions 531 and 543.

For all $\mathrm{BCV}$ isolates studied, the region located between $\mathrm{S}$ and $\mathrm{M}$ genes (ORF4) apparently encodes for two non-structural proteins of 4,9 and 4,8 $\mathrm{kDa}$ and comprises a total of $302 \mathrm{nt}$. In comparison to $\mathrm{BCV}$ isolates, the $\mathrm{HEV}$ and $\mathrm{HCV}-\mathrm{OC} 43$ showed a major deletion in the region corresponding to ORF4. However, a specific anti-sense substitution was identified at aa position 88 of the putative $4,9 \mathrm{kDa}$ protein of $\mathrm{RBCV}$ isolates resulting in 29 rather than 43 aa residues. The ORF5, encoding for a $12,7 \mathrm{NS}$ protein and the $9,5 \mathrm{kDa}$ E protein, was highly conserved among $\mathrm{BCV}$ isolates studied.

\section{ACKNOWLEDGMENTS}

This work was supported by the National Science and Engineering Research Council of Canada

\section{REFERENCES}

Benfield DA, Saif LJ (1990) Cell culture propagation of a coronavirus isolated from cows with winter dysentery. J Clin Microbiol 28: 1454-1457

Chomczynski P, Sacchi N (1987) Single-step method of RNA isolation by acid guanidium thiocyanate-phenol-chloroform extraction. Ann Biochem 162: 156-159

Chouljenko VN, Kousoulas KG, Lin X, Storz, J (1998) Nucleotide and predicted amino acid sequences of all genes encoded by the 3 ' genomic portion $(9.5 \mathrm{~kb})$ of respiratory bovine coronaviruses and comparisons among respiratory and enteric coronaviruses. Virus genes $17: 33-42$

Dea S, Roy RS, Begin, ME (1980) Bovine coronavirus isolation in cell cultures. Am J Vet Res 41, 30-38.

Dea S, Michaud L, Milane G (1995) Comparison of bovine coronavirus isolates associated with neonatal calf diarrhoea and winter dysentery in adult dairy cattle in Québec. J Gen Virol 76, 1263-1270 
Dea S, Tijssen P (1989) Antigenic and polypeptide structure of turkey enteric coronaviruses as defined by monoclonal antibodies. J Gen Virol 70:,1725-1741

Deregt D, Babiuk LA (1987) Monoclonal antibodies to bovine coronavirus: characteristics and topographical mapping of neutralizing epitopes on the E2 and E3 glycoproteins. Virology 161, 410-420

Mebus CA, Stair EL, Rhodes MB, Twiehaus MJ (1973) Neonatal calf diarrhea: propagation, attenuation. and characteristics of a coronavirus-like agent. Am J Vet Res 34, $145-150$

Milane G, Kourtesis AB, Dea S (1997) Characterization of monoclonal antibodies to the hemagglutinin-esterase glycoprotein of a bovine coronavirus associated with winter dysentery and cross-reactivity to field isolates. J Clin Microbiol 35: 33-40.

Mounir S., and Talbot, P.J. (1993) Human coronavirus OC43 RNA lacks two open reading framed located downstream of the S gene of bovine coronavirus. Virology 192, 355-360.

Parker MD, Yoo D, Babiuk LA (1990) Expression and secretion of the bovine coronavirus hemagglutinin-esterase glycoprotein by insect cells infected with recombinant baculoviruses. J Virol 64, 1625-1629,

Reynolds DJ, Debney T J, Hall GA, Thomas LH, Parsons K R (1985) Studies on the relationship between coronaviruses from the intestinal and respiratory tracts of calves. Arch Virol 85, 71-83,

Spaan WD, Cavanagh D, Horzinek MC (1988) Coronaviruses: structure and genome expression. J Gen Virol 69, 2939-2952

Storz J, Stine L, Liem A, et al. (1996) Coronavirus isolation from nasal swabs samples in cattle with signs of respiratory tract disease after shipping. JAVMA 208, 1452-1454

Tsunemitsu H, Saif LJ (1995) Antigenic and biological comparisons of bovine coronaviruses derived from neonatal calf diarrhea and winter dysentery of adult cattle. Arch Virol 140, 1303-1311

Vautherot JF, Madelaine MF, Boireau P, Laporte J (1992). Bovine coronavirus peplomer glycoproteins: detailed antigenic analysis of S1, S2 and HE. J Gen Virol 73, 1725-1737. 